\title{
Glycemic Control among Medical Outpatients in Enugu: A Cross Sectional Survey
}

\author{
Obinna Donatus Onodugo1, Birinus Adikaibe Ezeala-Adikaibe ${ }^{1,2 *}$, Obumneme Benneth Anyim², \\ Pascaline Onodugo' ${ }^{1}$ Ijeoma Nnene Anyim ${ }^{3}$, Nkeiruka Chigekwu Mbadiwe ${ }^{1}$, Ekenechukwu Young1, \\ Michael Abonyi², Gideon Anigbo², Ifeoma Ulasi' ${ }^{1}$, Uzoma Chukwunonso Okechukwu²
}

${ }^{1}$ Department of Medicine, University of Nigeria Teaching Hospital, Enugu, Nigeria

${ }^{2}$ Department of Medicine, Enugu State University Teaching Hospital, Enugu, Nigeria

${ }^{3}$ Department of Pediatrics, University of Nigeria Teaching Hospital, Enugu, Nigeria

Email: ^birinusadikaibe@gmail.com

How to cite this paper: Onodugo, O.D. Ezeala-Adikaibe, B.A., Anyim, O.B., Onodugo, P., Anyim, I.N., Mbadiwe, N.C., Young, E., Abonyi, M., Anigbo, G., Ulasi, I. and Okechukwu, U.C. (2019) Glycemic Control among Medical Outpatients in Enugu: A Cross Sectional Survey. Journal of Diabetes Mellitus, 9, 50-61.

https://doi.org/10.4236/jdm.2019.92006

Received: March 20, 2019

Accepted: May 28, 2019

Published: May 31, 2019

Copyright $\odot 2019$ by author(s) and Scientific Research Publishing Inc. This work is licensed under the Creative Commons Attribution International License (CC BY 4.0).

http://creativecommons.org/licenses/by/4.0/ cc) (i) Open Access

\begin{abstract}
Background: Diabetes in Nigeria presents a rising public health challenge and many cases are probably undetected. Poor glycemic control is a risk factor to both micro and macro vascular complications of diabetes and a major factor in the burden of the disease world-wide. The aim of the present study was to determine the pattern of glycemic control among adult diabetes patients attending a medical outpatient clinic in Enugu. Methods: Using a semi-structured questionnaire, we conducted a cross sectional descriptive study of patients with diabetes attending the medical out-patient clinic of one of the tertiary Hospitals in Enugu, Nigeria. Good glycemic control was defined as fasting blood glucose of less than $100 \mathrm{mg} / \mathrm{dl}$. Study duration was 6 months. Statistical analyses were done using SPSS software. Results: A total of 119 participants were recruited for the study: 74 (62.2\%) females and 45 males $(37.8 \%)$ with a mean age of $62.2(11.7)$ years. The mean systolic and diastolic blood pressure was 138.4 (24.3) $\mathrm{mmHg}$ and 81.2 (12.9) $\mathrm{mmHg}$ respectively. Eight (6.7\%) had a documented history of diabetes-related coma in the past. The mean fasting blood glucose was $127.9(22.4) \mathrm{mg} / \mathrm{dl}$. Good, fair and poor glycemic control was achieved in $16.8 \%, 30.3 \%$ and $63 \%$ (52.9\%) respectively. Correlation statistics showed that low level of adherence and abstaining from alcohol/tobacco are correlated with poor glycemic control. Conclusion: Majority (52.9\%) of patients with diabetes attending a tertiary health center in Enugu, Nigeria has poor glycemic control status. Medication adherence and substance use are correlated with poor control.
\end{abstract}

\section{Keywords}

Diabetes, Glycemic Control, Enugu, Nigeria 


\section{Introduction}

Diabetes is a common non-communicable disorder in South East Nigeria with a current prevalence as high as $11 \%$ [1]. Diabetes in the country presents a rising public health challenge [2] [3] [4] and many cases are probably undetected [1] [2] [3]. Poor glycemic control is a risk factor for both micro and macro vascular complications of diabetes. It is also a major factor in the burden of the disease and has been documented in several studies from Sub-Saharan Africa [5]-[11]. Poor glycemic control remains a challenge worldwide even in developed countries [12]-[18].

Good glycemic control has been defined in type 2 diabetes as fasting plasma glucose level of between 80 and $110 \mathrm{mg} / \mathrm{dl}$ [19]. Poor glycemic control has been related to factors such as modality of treatment, age, gender, access to care, diet, obesity, systolic blood pressure, physical activity and level of knowledge of patients and their care givers [5] [6] [12] [14] [15] [17]. In many Nigerian communities, there is a high rate of herbal-medication use as well as poor knowledge attitude and practice of diabetes [4] [5] [6] [20].

Documented prevalence of glycemic control varies widely and may reach as high as $79 \%$ in some studies depending on methodology used [7] [19] [21] [22] [23] [24] [25]. In Iran more than $64.4 \%$ of the patients have poor overall glycemic control [16]. In sub-Saharan Africa including Nigeria this figure has consistently remained high [5] [7] [12] [23] [24]. A study from the Niger Delta region of Nigeria reported a rate of 55\% [5] while others have reported rates ranging from $34 \%$ - 65.7\% [5] [6] [11] [23] [24].

Although most of these studies used $\mathrm{HbA1C}$ in their reports, some also used fasting blood glucose measurements. Fasting blood glucose measurement using glucometers is cheaper and readily available. Furthermore, HbA1c could miss out some patients at high risk for diabetic complications following acute changes in blood glucose levels. To the best of our knowledge, only one study has evaluated glycemic control among people living with diabetes in Enugu south-east Nigeria [11]. The aim of the present study was to determine the pattern of glycemic control among adult diabetic patients attending a medical outpatient clinic in Enugu. Detecting the pattern of glycemic control in a hospital setting will form an important public and patient educational tool aimed at prevention of the complications of diabetes.

\section{Methods}

We conducted a cross sectional descriptive study of patients with diabetes who were attending the medical out-patient clinic of the Enugu State University of Science and Technology Teaching Hospital Enugu, Enugu Nigeria. At the time of the study, the hospital had 350 beds distributed among the various specialties with 50 inpatient beds for adult admissions for medical cases. All consecutive consenting patients with were recruited. Diabetes was considered the primary 
diagnosis in all cases and any other disease in the patients as a comorbidity. Patients with acute febrile illness, diabetic ulcers, first hospital visit for diabetes or taking steroid were excluded. Patients with symptoms suggestive of acute complications of diabetes were also excluded.

Ethical clearance was obtained from the ethics committee of the Enugu State University Teaching Hospital. Ethical conduct was maintained during data collection and throughout the research process. Informed consent was obtained from each study participant. Study duration was 6 months (June to November 2013).

\subsection{Study Design}

Data was obtained using a semi-structured questionnaire designed by one of the authors (E_ABA) after reviewing similar studies [6] [9] [11] [15] [16]. The full methodology of the study has been reported elsewhere (see appendix) [20]. Data on selected sociodemographic characteristics and lifestyle behaviors including smoking, drinking and use of herbal/traditional medicine. Past medical history was obtained from the subjects and confirmed from the case notes. All participants were interviewed in the clinic after they had rested in a sitting position for 5 - 10 minutes. Blood pressure was measured thrice by means of mercury sphygmomanometer (Chris Aloy ${ }^{\circ}$ ) according to the guidelines of the European Society of Hypertension [26]. Fasting blood glucose was measured using a glucometer (Fine test premium, Infobia Co. Ltd., Dongan-gu, South Korea) after overnight fasting. Fasting blood glucose was obtained once during recruitment in all the patients.

\subsection{Definition of Terms}

Diabetes was defined as documented evidence of previous diabetes and/or use of hypoglycemic agents in patients' case notes. Patients attending their first hospital visit for diabetes were excluded. Fasting blood glucose $<110 \mathrm{mg} / \mathrm{dl}$ was considered as good control, $110-125 \mathrm{mg} / \mathrm{dl}$ as fair and FBS $\geq 126 \mathrm{mg} / \mathrm{dl}$ as poor control.

Weight was measured using a bathroom scale in kilograms. Height was measured in centimeters with the patient standing erect on a flat surface. Body mass index (BMI) was calculated as weight $(\mathrm{Kg})$ divided by squared height $\left(\mathrm{m}^{2}\right)$.

A patient was considered to have hypertension if the systolic blood pressure (SBP) was $\geq 140 \mathrm{mmHg}$ and/or diastolic blood pressure (DBP) of $\geq 90 \mathrm{mmHg}$ and/or recorded use of anti-hypertensive drugs. Recent tobacco and alcohol use were defined as use of tobacco in any form and consumption of alcohol within the last 4 weeks. Occupation was defined as the primary job which takes at least $50 \%$ of the working hours in a week. Other medical co-morbidities were defined using standard criteria or past medical history diagnosed by a qualified personnel (doctors). Level of education was the individual's highest educational (formal) attainment. 


\subsection{Study Instruments}

The Morinsky-Green Medication adherence scale [27] was used to estimate medication adherence. Answers consistent with adherence were scored as 0 and answers consistent with non-adherence were scored as 1 . For the purpose of the index study the scores are tallied and graded into high adherence $(0-2)$, medium adherence (3 - 5) and low adherence (6-8).

\subsection{Statistical Methods}

For database management and statistical analyses, SPSS version23 (IBM Corporation, New York, USA) was used. Data were presented in tables. For continuous variables, mean values and standard deviation were calculated. Rates were expressed as percentages. Categorical values were compared using the Chi Square test. Mean values were compared using the independent $t$-test. In all, $p$ value of $<0.05$ was regarded as statistically significant. Conclusions were drawn at $95 \%$ confidence interval.

\section{Results}

\section{Characteristics of the Participants}

A total of 119 cases of diabetes who have attended the clinic at least more than once were recruited for the study. They were made of 74 (62.2\%) females and 45 males (37.8\%) (Table 1). The mean age (sd) of the patients was 62.2 (11.7) years with a range of 36 to 89 years. The age distribution is shown in Figure 1. Males were older than females by 10 years $(\mathrm{P}<0.01)$. Although females were shorter $(\mathrm{P}$ $<0.01)$, they had a higher mean BMI $(\mathrm{P}<0.01)$. Patients came equally from both urban and rural areas. The level of education, occupation and other characteristics of the population are also shown in Table 1. The mean systolic and diastolic blood pressure was similar in bother sexes. Medical history showed that most had hypertension 101 (84.9\%) and chronic headache 52 (43.7\%). Eight (6.7\%) had a documented history of diabetes-related coma in the past. Of all comorbidities only Parkinson disease was commoner in males $(P=0.03)$. Seventeen (14.3\%) patients were current tobacco users, 90 (75.6\%) used herbal or alternative medicine in one form or the other in the past and 33 (27.7\%) used alcohol. Medication adherence measured by the Morinsky-Green Medication adherence scale is shown in Table 1. Adherence was similar in males and females $(P=0.6)$.

The mean fasting blood glucose is shown in Table 1 and the distribution in Figure 2. Good blood glucose control $(<110 \mathrm{mg} / \mathrm{dl})$ was only achieved in $16.8 \%$ while another $30.3 \%$ had a fair control and $63(52.9 \%)$ achieved poor glycemic control. The distribution of glycemic control was not statistically significant in any of the categories considered (Table 2).

Correlation statistics using Spearman Rho statistic showed that low level of adherence and abstaining from alcohol/tobacco correlated with poor glycemic control (Table 3). 
Table 1. Patients' characteristics and other variables.

\begin{tabular}{|c|c|c|c|c|}
\hline Characteristic & Females & Males & Total & $\mathrm{P}$-value \\
\hline N (\%) & $74(62.2)$ & $45(37.8)$ & $119(100)$ & $<0.01$ \\
\hline Age, years mean \pm sd & $58.4 \pm 11.2$ & $68.2 \pm 10.1$ & $62.2(11.7)$ & $<0.01$ \\
\hline Height, $\mathrm{cm}$ mean $\pm \mathrm{sd}$ & $158.1 \pm 6.3$ & $162.3 \pm 8$ & $159.7(7.3)$ & $<0.01$ \\
\hline Weight, $\mathrm{kg}$ mean $\pm \mathrm{sd}$ & $71.4 \pm 15.2$ & $68.9 \pm 11.4$ & $70.4(13.9)$ & 0.34 \\
\hline Body mass index, $\mathrm{kg} / \mathrm{m}^{2}$ mean $\pm \mathrm{sd}$ & $28.6 \pm 5.8$ & $26.1 \pm 3.8$ & $27.6(5.2)$ & 0.01 \\
\hline \multicolumn{5}{|l|}{ Place of residence $n,(\%)$} \\
\hline Urban & $55(74.3)$ & $31(68.9$ & $86(72.3)$ & \\
\hline Rural & $14(31.1)$ & $19(25.7)$ & $33(27.7)$ & 0.52 \\
\hline \multicolumn{5}{|l|}{ Level of education n, (\%) } \\
\hline Primary & $28(37.4)$ & $22(50)$ & $50(42.4)$ & \\
\hline Secondary & $4(5.4)$ & $9(20.5)$ & $13(11)$ & \\
\hline Tertiary & $42(56.8)$ & $13(29.5)$ & $55(46.6)$ & $<0.01$ \\
\hline \multicolumn{5}{|l|}{ Occupation n, (\%) } \\
\hline Retired & $11(15.3)$ & $24(54.5)$ & $35(30.2)$ & \\
\hline Office workers & $21(29.4)$ & $5(11.4)$ & $26(22.4)$ & \\
\hline Business & $19(26.4)$ & $4(9.1)$ & $23(19.8)$ & \\
\hline Farmers & $11(15.3)$ & $3(6.8)$ & $14(12.1)$ & \\
\hline Artisans & $1(1.4)$ & $8(18.2)$ & $9(7.8)$ & \\
\hline Unemployed & $11(14.9)$ & $1(2.2)$ & $12(10.1)$ & \\
\hline \multicolumn{5}{|l|}{ Peripheral hemodynamics, mean $\pm s d$} \\
\hline Systolic pressure, $\mathrm{mm} \mathrm{Hg}$ & $138.3 \pm 25.3$ & $138.6 \pm 23.8$ & $138.4(24.3)$ & 0.95 \\
\hline Diastolic pressure, $\mathrm{mm} \mathrm{Hg}$ & $81.6 \pm 11.8$ & $80.5 \pm 14.7$ & $81.2(12.9)$ & 0.65 \\
\hline \multicolumn{5}{|l|}{ Measurements on blood, mean \pm sd } \\
\hline Glucose, mg/dl & $128 \pm 22.7$ & $127.7 \pm 22.4$ & $127.9(22.4)$ & 0.95 \\
\hline \multicolumn{5}{|l|}{ Medical history n, (\%) } \\
\hline Hypertension & $62(83.8)$ & $39(86.7)$ & $101(84.9)$ & 0.67 \\
\hline Chronic headache & $32(43.2)$ & $20(44.4)$ & $52(43.7)$ & 0.9 \\
\hline Arthritis & $43(58.1)$ & $25(55.6)$ & $68(57.1)$ & 0.79 \\
\hline Stroke & $8(10.8)$ & $5(11.1)$ & $13(10.9)$ & 0.96 \\
\hline Parkinson's disease & $3(4.1)$ & $7(15.6)$ & $9(7.6)$ & 0.03 \\
\hline Heart failure & $6(8.1$ & $5(11.1)$ & $11(9.2)$ & 0.58 \\
\hline Others & $11(24.4)$ & $9(12.2)$ & $20(16.8)$ & $<0.01$ \\
\hline Past History of Diabetic Coma n, (\%) & $4(5.4)$ & $4(8.9)$ & $8(6.7)$ & 0.46 \\
\hline \multicolumn{5}{|l|}{ Lifestyle n, (\%) } \\
\hline Current use of tobacco, n (\%) & $5(6.8)$ & $12(26.7)$ & $17(14.3)$ & $<0.01$ \\
\hline Used herbal medicine & $57(77)$ & $33(73.3)$ & $90(75.6)$ & 0.65 \\
\hline Use of alcohol, & $20(27)$ & $13(28.9)$ & $33(27.7)$ & 0.84 \\
\hline \multicolumn{5}{|l|}{ Morinsky Adherence Score n, (\%) } \\
\hline High $(0-2)$ & $46(62.2)$ & $29(64.4)$ & $75(63)$ & \\
\hline Medium (3 - 5) & $21(28.4)$ & $14(31.1)$ & $35(29.4)$ & \\
\hline Low $(6-8)$ & $7(9.5)$ & $2(4.4)$ & $9(7.6)$ & 0.6 \\
\hline
\end{tabular}

$\mathrm{P}$-values are for the sex differences. 
Table 2. Level of glycemic control among the participants.

\begin{tabular}{|c|c|c|c|c|}
\hline \multirow{2}{*}{ Variable } & \multicolumn{3}{|c|}{ Level of control } & \multirow[b]{2}{*}{$\mathrm{P}$-value } \\
\hline & Good control & Fair & Poor & \\
\hline Total & $20(16.8)$ & $36(30.3)$ & $63(52.9)$ & \\
\hline Male & $10(22.2)$ & $11(30.6)$ & $24(38.1)$ & \\
\hline Female & $10(13.5)$ & $25(33.8)$ & $39(61.9)$ & 0.36 \\
\hline \multicolumn{5}{|l|}{ BMI } \\
\hline$<18.5$ & $1(20)$ & $3(60)$ & $1(20)$ & \\
\hline $18.5-24.9$ & $7(19.4)$ & $7(19.4)$ & $22(61.1)$ & \\
\hline $25-29.9$ & $6(13)$ & $12(26.1)$ & $28(60)$ & \\
\hline$\geq 30$ & $6(18.8)$ & $14(43.8)$ & $12(37.5)$ & 0.17 \\
\hline Age Group (years) & - & - & - & - \\
\hline $36-49$ & - & $3(20)$ & $12(80)$ & \\
\hline $50-59$ & $4(12.1)$ & $13(39.4)$ & $16(48.5)$ & \\
\hline $60-69$ & $10(24.4)$ & $12(29.3)$ & $19(46.3)$ & \\
\hline$\geq 70$ & $6(20)$ & $8(26.7)$ & $16(25.4)$ & 0.19 \\
\hline \multicolumn{5}{|l|}{ Place of residence } \\
\hline Urban & $12(14)$ & $31(36)$ & $43(50)$ & \\
\hline Rural & $8(24.2)$ & $5(15.2)$ & $20(60.6)$ & 0.07 \\
\hline \multicolumn{5}{|l|}{ Level of education } \\
\hline Primary & $10(20)$ & $12(24)$ & $28(56)$ & \\
\hline Secondary & $3(23.1)$ & $1(7.7)$ & $9(69.2)$ & \\
\hline Tertiary & $7(12.7)$ & $22(40)$ & $26(47.3)$ & 0.15 \\
\hline \multicolumn{5}{|l|}{ Occupation } \\
\hline Working & $9(12.5)$ & $25(34.7)$ & $38(52.8)$ & \\
\hline Unemployed & $2(16.7)$ & $3(25)$ & $7(58.3)$ & \\
\hline Retired & $9(25.7)$ & $8(22.9)$ & $18(51.4)$ & 0.45 \\
\hline Comorbidity & - & - & - & - \\
\hline None-one & $5(17.2)$ & $5(17.2)$ & $19(65.5)$ & \\
\hline Two-Three & $13(17.3)$ & $25(33.3)$ & $37(49.3)$ & \\
\hline Four-five & $2(13.3)$ & $6(40)$ & $7(46.3)$ & 0.32 \\
\hline
\end{tabular}

Table 3. Correlates of good/fair glycemic control in the patients.

\begin{tabular}{cc}
\hline Age & R (P-value) \\
Gender (male 1, female 0) & $-0.05(0.58)$ \\
Body Mass Index & $-0.01(0.95)$ \\
Occupational status (1 working, 0 not working) & $-0.04(0.67)$ \\
Level of education (1 primary, 2 secondary, 3 tertiary) & $-0.00(0.97)$ \\
Residence (1 urban, 0 rural) & $-0.12(0.18)$ \\
Level of adherence (1 high, 2 moderate, 3 low) & $0.01(0.3)$ \\
Substance use (2, both, 1 either, 0 none) & $0.19(0.04)$ \\
Presence of comorbidities (1 yes, 0 no) & $-0.19(0.04)$ \\
History of coma (1 yes, 0 no) & $-0.06(0.49)$ \\
\hline
\end{tabular}

${ }^{*}$ Use of alcohol and/or tobacco. 


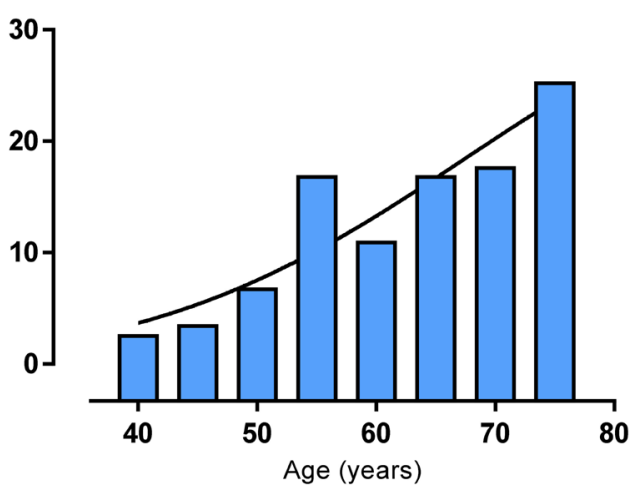

Figure 1. Age distribution of the patients.

Frequency distribution fasting blood glucose

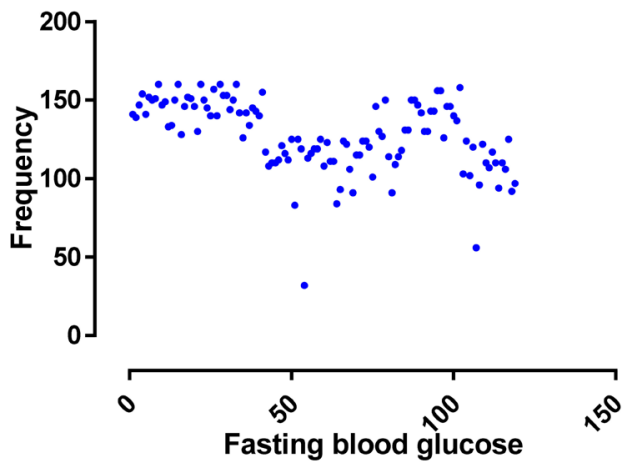

Figure 2. Distribution of fasting Blood glucose in the study population.

\section{Discussion}

The findings of this study reveal an overall poor glycemic control among medical out-patients in one of the major hospitals in Enugu metropolis. A total of 63 (52.9\%) had poor control. Glycemic control was similar in males and females, in all age groups and all categories studied. It was slightly better among rural dwellers. Only the poor medication adherence and non-substance use correlated with poor control.

Individuals with FBG greater than $125 \mathrm{mg} / \mathrm{dl}$ are at greater risk of developing chronic complications of diabetes and other cardiovascular complications like strokes and myocardial infarction [19]. Therefore, poor glycemic control status in diabetic patients should be considered a target for public health authorities as well as health educationists.

The rate of poor glycemic control in the index study is within the range reported in Nigeria and the sub-continent [5]-[11] [21] [23] [25]. Unlike in most of these studies, we used fasting blood glucose as an indicator of control instead of HbA1C. Although fasting blood glucose offers only a narrow window into the overall blood glucose level of the patient, it is often the most available method of checking glycemic control in our setting and often more likely to be available at home, health centers and most private hospitals. It therefore forms the basis for 
day to day management of patients and adjustment of medications.

Females and younger patients had non-statistical higher rates of poor control. This is similar to previous studies [5] [15] [16] [28] [29]. The reasons for relationship between age, gender and glycemic control may be multifaceted. Better glycemic control has been associated with the duration of diabetes [17] and by implication older individuals. Other factors such as multiple comorbidities in older individual, use of multiple medications and hence increased pill burden, dependency and poverty may all be contributory. The high proportion of females reported in this study may be attributed to fact that females were also younger who are known to be less adherent and have poor health seeking behaviour [30] [31]. The index report is similar to a previous study from Iran [15].

Rural dwellers also had a non-significant higher rate good glycemic control when compared to urban dwellers. Reasons for this may be attitudinal which may be linked to pressure from family members and relatives to try one cure after the other as well as prevalent poor knowledge and practice of diabetes [5] [6]. The non-significant finding between urban and rural dwellers is similar to was reported from other studies [6] [16].

There was no significant difference between patients who were employed and those who were not at the time of the study. The relationship between employment status and affordability of health care may not always be straightforward. It is important to remember that most patients in the African context have very high rates of social support and may not be fully responsible for their medical bills [32]. Furthermore, being actively engaged during working hours may interfere with taking medications especially insulin.

Similar to other studies BMI did not correlate with glycemic control [15] [16]. One suggested reason for the lack of correlation between BMI and glycemic control was the fact that patients with diabetes gain weight with age irrespective of glucose control [16].

Glycemic control also did not differ significantly between patients with different levels of education. Several studies have reported that formal education significantly improves adherence [31] [33] [34] which may contribute to glycemic control. However, higher level of education does not necessarily enhance the understanding of the disease and its complications [35].

An interesting finding is the negative correlation of substance use (alcohol and tobacco) with poor glycemic control. It is interesting to note that neither of these substances correlated with glycemic control alone but did so when combined. Reasons for this are not clear because of the limitations of the index study. It is an established fact that both tobacco and alcohol may worsen the cardiovascular complications of diabetes just as poor glycemic control. Hence one may be inclined to suggest that those who had poor control and/or who presented with complications were more likely to abstain. In Saudi Arabia, researchers also did not find any correlation between smoking and glycemic control [16]. The history of previous diabetic coma was recorded in few cases and 
did not correlate with the level of glycemic control. Diabetic Keto-acidosis has been reported to predict poor long term glycemic control in children [36] [37]. Previous history of coma in the index study may not only reflect poor control but also severity at diagnosis due to high level of unawareness. Medical comorbidities were common among our patients because of their age distribution. Comorbidities increase pill load leading to drug fatigue and hence non-adherence to medications including anti diabetic drugs. However, there was no correlation between the number of associated comorbidities and level of control which is similar to some studies [38].

Improving glycemic control remains a key factor in the management of diabetes and prevention of complications. In a region with high levels of infectious diseases and growing burden of metabolic disorders the measures towards improving glycemic control cannot be overemphasized. The apparent lack of significant correlates in this study suggests that the answer to this problem may lie elsewhere-patients education and lifestyle changes that are associated with it.

\section{Limitations}

This study has some limitations. First, the time between the previous estimation of FPG and the current FPG was not the same for all patients. Secondly, as previously stated $\mathrm{HbAlc}$ is more useful in estimating long term control. Thirdly, our study did not include data on diet and lifestyle changes required in the management of such patients. Furthermore, we recruited patients from a teaching hospital set-up which may include many cases of difficult-to-manage cases as well as complicated cases of diabetes which in turn may limit the generalization of our findings.

\section{Conclusion}

The majority of the patients in the current study had poor glycemic control status. The level of medication adherence and substance use are correlated with poor control. The index study suggests that many factors may be related to glycemic control which may include patients' education and drug selection. Further research should be conducted to evaluate patient and physician centered factors in glycemic control.

\section{Conflicts of Interest}

The authors declare no conflicts of interest regarding the publication of this paper.

\section{References}

[1] Ezeala-Adikaibe, B.A., Mbadiwe, N., Okwara, C., Onodugo, O., Onyekonwu, C., Ijoma, U., Ekenze, O.S., Orjioke, C., Chime, P., Aneke, E., Nwatu, C.B., Young, E. and Anyim, O. (2018) Diabetes and Pre-Diabetes among Adults in an Urban Slum in South East Nigeria. Journal of Diabetes Mellitus, 8, 131-144. https://doi.org/10.4236/jdm.2018.84013 
[2] Ejike, C.E.C.C., Uka, N.K. and Nwachukwu, S.O. (2015) Diabetes and Prediabetes in Adult Nigerians: Prevalence, and Correlations of Blood Glucose Concentrations with Measures of Obesity. African Journal of Biochemistry Research, 9, 55-60. https://doi.org/10.5897/AJBR2015.0817

[3] Chinenye, S. and Young, E. (2011) State of Diabetes Care in Nigeria: A Review. Nigeria Health Journal, 11, 101-109.

[4] Akinjinmi, A.A., Adeyooye, O.A., Akingbade, O.A. and Okerentugba, P.O. (2014) Prevalence of Diabetes Mellitus in Abeokuta, Ogun State, Researcher, 6, 73-75.

[5] Ufuoma, C., Godwin, Y.D., Kester, A.D. and Ngozi, J.C. (2016) Determinants of Control among Persons with Type 2 Diabetes Mellitus in Niger Delta. Sahel Medical Journal, 19, 190-195. https://doi.org/10.4103/1118-8561.196361

[6] Odili, V.U., Isiboge, P.D and Eregie, A. (2011). Patients' Knowledge of Diabetes Mellitus in a Nigerian City. Tropical Journal of Pharmaceutical Research, 10, 637-642. https://doi.org/10.4314/tjpr.v10i5.13

[7] Frier, B.M. and Fisher, M. (2010) Diabetes Mellitus. In: Colledge, N.R., Walker, B.R. and Ralston, S.H., Eds., Davidson's Principles and Practice of Medicine, $21^{\text {st }}$ Edition, Churchill Livingstone Elsevier, Edinburgh, 795-833. https://doi.org/10.1016/B978-0-7020-3085-7.00021-3

[8] Musenge, E.M., Manankov, A., Mudenda, B. and Michelo, C. (2014) Glycaemic Control in Diabetic Patients in Zambia. Pan African Medical Journal, 9, 354. https://doi.org/10.11604/pamj.2014.19.354.5264

[9] Phiri, M.P., Chimwemwe, M.J. and Damson, K. (2014) Prevalence and Correlates of Diabetes Mellitus in Malawi: Population-Based National NCD STEPS Survey. BMC Endocrine Disorders, 14, 41. https://doi.org/10.1186/1472-6823-14-41

[10] Adebisi, S.A. (2009) Glycated Haemoglobin and Glycaemic Control of Diabetics in Ilorin. Nigerian Journal of Clinical Practice, 12, 87-91.

[11] Otieno, C.F., Kariuki, M. and Nganga, L. (2003) Quality of Glycaemic Control in Ambulatory Diabetics at the Out-Patient Clinic of Kenyatta National Hospital. East African Medical Journal, 80, 406-410. https://doi.org/10.4314/eamj.v80i8.8731

[12] Okafor, C.I. and Ofoegbu, E.N. (2012) Control to Goal of Cardiometabolic Risk Factors among Nigerians Living with Type 2 Diabetes Mellitus. Nigerian Journal of Clinical Practice, 15, 15-18. https://doi.org/10.4103/1119-3077.94089

[13] Ntui, I., Udoh, A.E., Esiere, K.-U.S., Essien, O. and Egbe, E.R. (2006) The Pattern of Dietary Habits and Control of Diabetics in Eastern Nigeria. Pakistan Journal of $\mathrm{Nu}^{-}$ trition, 5, 43-45. https://doi.org/10.3923/pjn.2006.43.45

[14] Bi, Y., Zhu, D., Cheng, J., Zhu, Y., Xu, N., Cui, S., Li, W., Cheng, X., Wang, F., Hu, Y., Shen, S. and Weng, J. (2010) The Status of Control: A Cross-Sectional Study of Outpatients with Type 2 Diabetes Mellitus across Primary, Secondary, and Tertiary Hospitals in the Jiangsu Province of China. Clinical Therapy, 32, 973-983. https://doi.org/10.1016/j.clinthera.2010.05.002

[15] Mendes, B.V.A., Fittipaldi, A.S.J., Neves, C.S.R., Celestino, S.R., Chacra, R.A. and Moreira Jr., D.E. (2010) Prevalence and Correlates of Inadequate Glycaemic Control: Results from a Nationwide Survey in 6,671 Adults with Diabetes in Brazil. Acta Diabetologica, 47, 137-145. https://doi.org/10.1007/s00592-009-0138-Z

[16] Janghorbani, M. and Amini, M. (2012) Patterns and Predictors of Long-Term Control in Patients with Type 2 Diabetes. International Scholarly Research Network Endocrinology, 2012, Article ID: 526824. https://doi.org/10.5402/2012/526824

[17] Al-Nuaim, A.R., Mirdad, S., Al-Rubeaan, K., Al-Mazrou, Y., Al-Attas, O. and 
Al-Daghari, N. (1998) Pattern and Factors Associated with Control of Saudi Diabetic Patients. Annals of Saudi Medicine, 18, 109-112. https://doi.org/10.5144/0256-4947.1998.109

[18] Reisig, V., Reitmeir, P., Döring, A., Rathmann, W. and Mielck, A. (2007) Social Inequalities and Outcomes in Type 2 Diabetes in the German Region of Augsburg: A Cross-Sectional Survey. International Journal of Public Health, 52, 158-165. https://doi.org/10.1007/s00038-007-5077-2

[19] Arai, K., Hirao, K., Matsuba, I., Takai, M., Matoba, K., Takeda, H., Kanamori, A., Yamauchi, M., Mori, H. and Terauchi, Y. (2009) The Status of Control by General Practitioners and Specialists for Diabetes in Japan: A Cross-Sectional Survey of 15,652 Patients with Diabetes Mellitus. Diabetes Research and Clinical Practice, 83, 397-401. https://doi.org/10.1016/j.diabres.2008.11.036

[20] Ezeala-Adikaibe, B.A., Mbadiwe, N., Okudo, G., Nwosu, N. and Nwobodo, N. (2017) Factors Associated with Medication Adherence among Hypertensive Patients in a Tertiary Health Center: A Cross-Sectional Study. Achieves of Community Medicine and Public Health, 3, 24-31. https://doi.org/10.17352/2455-5479.000021

[21] Gudina, E.K., Amade, S.T., Tesfamichael, F.A. and Ram, R. (2011) Assessment of Quality of Care Given to Diabetic Patients at Jimma University Specialized Hospital Diabetes Follow-Up Clinic, Jimma, Ethiopia. BMC Endocrine Disorders, 11, 19. https://doi.org/10.1186/1472-6823-11-19

[22] Fox, K.M., Gerber Pharmd, R.A., Bolinder, B., Chen, J. and Kumar, S. (2006) Prevalence of Inadequate Control among Patients with Type 2 Diabetes in the United Kingdom General Practice Research Database: A Series of Retrospective Analyses of Data from 1998 through 2002. Clinical Therapy, 28, 388-395. https://doi.org/10.1016/j.clinthera.2006.03.005

[23] Yusuff, K.B., Obe, O. and Joseph, B.Y. (2008) Adherence to Anti-Diabetic Drug Therapy and Self-Management Practices among Type-2 Diabetics in Nigeria. Pharmacy World and Science, 30, 876-883. https://doi.org/10.1007/s11096-008-9243-2

[24] Adisa, R., Fakeye, T.O. and Fasanmade, A. (2011) Medication Adherence among Ambulatory Patients with Type 2 Diabetes in a Tertiary Healthcare Setting in Southwestern Nigeria. Pharmacy Practice (Granada), 9, 72-81. https://doi.org/10.4321/S1886-36552011000200003

[25] Khattab, M., Khader, Y.S., Al-Khawaldeh, A. and Ajlouni, K. (2010) Factors Associated with Poor Control among Patients with Type 2 Diabetes. Journal of Diabetes Complications, 24, 84-89. https://doi.org/10.1016/j.jdiacomp.2008.12.008

[26] O’Brien, E., Asmar, R., Beilin, L., Imai, Y., Mancia, G., Mengden, T., Meyers, M., Palatini, P., Parati, G., Pickering, T., Redon, J., Staessen, J., Stergiou, G. and Verdecchia, P. (2005) Practice Guidelines of the European Society of Hypertension for Clinic, Ambulatory and Self Blood Pressure Measurement. Journal of Hypertension, 23, 697-701. https://doi.org/10.1097/01.hjh.0000163132.84890.c4

[27] Morisky, D.E., Green, L.W. and Levine, D.M. (1986) Concurrent and Predictive Validity of a Self-Reported Measure of Medication Adherence. Medical Care, 24, 67-74. https://doi.org/10.1097/00005650-198601000-00007

[28] Shani, M., Taylor, T.R., Vinker, S., Lustman, A., Erez, R., Elhayany, A. and Lahad, A. (2008) Characteristics of Diabetics with Poor Control Who Achieve Good Control. Journal of the American Board of Family Medicine, 21, 490-496. https://doi.org/10.3122/jabfm.2008.06.070267

[29] Moreira Jr., E.D., Neves, R.C., Nunes, Z.O., de Almeida, M.C., Mendes, A.B., Fitti- 
paldi, J.A. and Abian, F.(2010) Control and Its Correlates in Patients with Diabetes in Venezuela: Results from a Nationwide Survey. Diabetes Research and Clinical Practice, 87, 407-414. https://doi.org/10.1016/j.diabres.2009.12.014

[30] Boima, V., Ademola, A.D., Odusola, A.O., Agyekum, F., Nwafor, C.E., Cole, H., Salako, B.B., Ogedegbe, G. and Tayo, B.O. (2015) Factors Associated with Medication Nonadherence among Hypertensives in Ghana and Nigeria. International Journal of Hypertension, 2015, Article ID: 205716. https://doi.org/10.1155/2015/205716

[31] Osamor, P.E. and Owumi, B.E. (2011) Factors Associated with Treatment Compliance in Hypertension in Southwest Nigeria. Journal of Health, Population and Nutrition, 29, 619-628. https://doi.org/10.3329/jhpn.v29i6.9899

[32] Ekeopara, C.A. (2012) The Impact of the Extended Family System on Socio-Ethical Order in Igboland. American Journal of Social Issues and Humanities, 2, 262-267.

[33] Ghods, A.J. and Nasrollahzadeh, D. (2003) Noncompliance with Immunosuppressive Medications after Renal Transplantation. Tissue Antigens, 60, 553-553. https://doi.org/10.1034/j.1399-0039.2002.00010.x

[34] DiMatteo, M.R. (2004) Social Support and Patient Adherence to Medical Treatment: A Meta-Analysis. Health Psychology, 23, 207-218. https://doi.org/10.1037/0278-6133.23.2.207

[35] Duca, L.M., Wang, B. and Rewers, A. (2017) Diabetic Ketoacidosis at Diagnosis of Type 1 Diabetes Predicts Poor Long-Term Control. Diabetes Care, 40, 1249-1255. https://doi.org/10.2337/dc17-0558

[36] Khanolkar, A.R., Amin, R., Taylor-Robinson, D., Viner, R.M., Warner, J., Gevers, E.F. and Stephenson, T. (2017) Diabetic Ketoacidosis Severity at Diagnosis and Glycaemic Control in the First Year of Childhood Onset Type 1 Diabetes-A Longitudinal Cohort Study. International Journal of Environmental Research and Public Health, 15, pii: E26. https://doi.org/10.3390/ijerph15010026

[37] El-Kebbi, I.M., Ziemer, D.C., Cook, C.B., Miller, C.D., Gallina, D.L. and Philips, L.S. (2001) Comorbidity and Control in Patients with Type 2 Diabetes. Achieves of Internal Medicine, 161, 1295-1300. https://doi.org/10.1001/archinte.161.10.1295

[38] Greenfield, S., Billimek, J., Pellegrini, F., Franciosi, M., DeBerardis, G., Nicolucci, A., Sherrie, H. and Kaplan, S.H. (2009) Comorbidity Affects the Relationship between Control and Cardiovascular Outcomes in Diabetes: A Cohort Study. Annals of Internal Medicine, 151, 854-860.

https://doi.org/10.7326/0003-4819-151-12-200912150-00005 